Fernanda Freire Fonseca

(iD) https://orcid.org/0000-0002-7369-2277

Daisy Moreira Cunhab

(iD) https://orcid.org/0000-0002-0702-8132

Estela Oliveira Vieirab

(iD) https://orcid.org/0000-0002-2191-5918

Celina Maria Modenac

(iD) https://orcid.org/0000-0001-5035-3427

\section{Implicações de novas tecnologias na atividade e qualificação dos servidores: Processo Judicial Eletrônico e a Justiça do Trabalho}

\author{
Implications of new technologies on the activity and training of \\ government officials: e-Filling and the Labor Justice
}

aTribunal Regional do Trabalho da $3^{\mathrm{a}}$ Região, Seção de Saúde Ocupacional. Belo Horizonte, MG, Brasil.

bUniversidade Federal de Minas Gerais. Belo Horizonte, MG, Brasil.

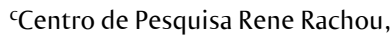
Fundação Oswaldo Cruz. Belo Horizonte, MG, Brasil.

Contato:

Fernanda Freire Fonseca

E-mail:

feffonseca@gmail.com

Os autores declaram que o trabalho não foi subvencionado e que não há conflitos de interesses.

O trabalho é baseado na dissertação de mestrado de Fernanda Freire Fonseca, intitulada Novas tecnologias na justiça do trabalho: impacto do processo judicial eletrônico na saúde e cotidiano de trabalho dos servidores, apresentada em 2015 ao Centro de Pesquisa René Rachou da Fiocruz Minas Gerais.

Os autores informam que o trabalho foi apresentado nas seguintes reuniões científicas: a) $15^{\circ}$ Congresso de Stress da ISMA-BR, $6^{\circ}$ Encontro Nacional de Qualidade de Vida no Serviço Público, em Porto Alegre, RS, 2015; b) $3^{\text {éme }}$ Congrés de la Societé Internationale d'Ergologie, em Provence, França, 2016; c) Congreso Iberoamericano de Investigación Cualitativa en Salud, em Barcelona, Espanha - 2016.

\section{Resumo}

Introdução: a informatização do processo judicial levantou questionamentos sobre as implicações dessa mudança no trabalho dos servidores do Judiciário. Objetivo: compreender as implicações da implementação do Processo Judicial Eletrônico na atividade e na qualificação de servidores da Justiça do Trabalho. Métodos: utilizou-se do referencial teórico da ergologia. Na perspectiva da pesquisa qualitativa, foram entrevistados 14 servidores de um Tribunal Regional do Trabalho, atendendo aos critérios de saturação e singularidade do discurso. As entrevistas foram realizadas entre 2014 e 2015, e analisadas em seu conteúdo na forma construtiva interpretativa. Discutiram-se os sentidos do trabalho, o trabalho prescrito e as representações dos trabalhadores sobre a implementação da nova tecnologia e sobre as qualificações e competências necessárias ao seu uso. Resultados: destacou-se o desconforto com a ausência de consulta prévia e com o treinamento insuficiente para o uso da ferramenta, uma vez que há exigências de novas qualificações. Evidenciou-se também um sentimento de aumento da demanda, associado ao alto envolvimento e comprometimento com o trabalho. Conclusão: considerando os custos pessoais e sociais acarretados por mudanças tecnológicas, em particular as demandas impostas aos trabalhadores e a necessidade de novas capacitações, a implementação de novas tecnologias deve ser sempre avaliada do ponto de vista de quem as utiliza.

Palavras-chave: novas tecnologias; saúde do trabalhador; ergologia; Poder Judiciário; formação profissional.

\begin{abstract}
Introduction: computerization of judicial processes raised questions on its implications on the Judiciary officials' work. Objective: to understand the implications of the e-Filling implementation on the Labor Justice officials' activities and training. Methods: theoretical framework based on ergology. From the perspective of qualitative research, 14 officials from a Regional Labor Court were interviewed, between 2014 and 2015, considering the criteria of saturation and uniqueness of speech. Constructive and interpretative content analysis was carried out. The following categories were defined for discussion: the meaning of work; prescribed work; workers' understanding on the implementation of the new technology and on the competences and skills required for its use. Results: since new skills were required, the discomfort resulting from lack of prior consultation and insufficient training on how to use the tool were highlighted. A feeling of increased demand associated with high involvement and commitment to the work was also perceived. Conclusion: considering the personal and social costs resulting from technological changes, particularly the demands imposed on workers and the need for new training programs, the implementation of new technologies must be assessed from the point of view of those who employ them.
\end{abstract}

Keywords: new technologies; occupational health; ergology; Judiciary; professional training. 


\section{Introdução}

É no e pelo trabalho que o indivíduo desenvolve suas capacidades intelectuais, estabelece relacionamentos e é reconhecido pelos demais ${ }^{1}$. Trajano e Cunha ${ }^{2}$ destacam: "são os meios/instrumentos com que se faz o trabalho - e não o que se faz que distinguem as diferentes épocas econômicas". Segundo Marx: "os meios de trabalho servem para medir o desenvolvimento da força humana de trabalho e indicam as condições sociais em que ele se realiza"3.

Todas as grandes etapas da evolução humana estão em relação dialética com os avanços de suas atividades laboriosas ${ }^{4}$. Segundo Schwartz, o trabalho sempre foi apreendido na mudança. É da natureza do trabalho humano que ele se modifica sempre e, assim, o grande desafio é compreendê-lo, visto que toda estabilidade percebida é relativa e temporária. Sabendo que não há uma ferramenta de interpretação que sirva para todas essas variabilidades, "é preciso estar atento à atividade das pessoas que trabalham"5.

Sobre os meios de trabalho, o uso das tecnologias é marcado pelo contexto devido à interdependência entre fatores econômicos, culturais, sociais etc. As escolhas sobre as formas de apropriação e os usos baseiam-se em práticas culturais, em valores sociais, em processos da comunicação e interesses econômicos ${ }^{6}$.

Exemplo emblemático das novas tecnologias no trabalho é a inserção do Processo Judicial Eletrônico, mais frequentemente chamado de PJe, no contexto do Judiciário brasileiro. $\mathrm{O}$ estabelecimento de meios eletrônicos para armazenagem dos elementos do processo altera a ferramenta de trabalho e também faz surgir um novo paradigma de catalogação e documentação dos atos processuais ${ }^{7}$.

Santos e Reis ${ }^{8}$, ao refletirem sobre o Processo Eletrônico no Tribunal Regional do Trabalho do Rio Grande do Sul (TRT-RS), dizem que "o balanço de um ano de funcionamento comprova que a principal vantagem é a agilidade". No entanto, todo processo de transformação vem acompanhado de desafios e resistências. Merlo, Souza Filho e Dornelles ${ }^{9}$ encontraram insatisfações com aspectos do sistema dos processos eletrônicos, tais como sistema de busca, visualização de documentos, estabilidade do sistema, velocidade da conexão e necessidade de salvar arquivos em outros sistemas. Segundo Marx, "a produtividade do trabalho depende não só da virtuosidade do trabalhador, mas também da perfeição de suas ferramentas"3. Neste sentido, Fígaro ${ }^{6}$ afirma que:
Um novo artefato não é imediata e indiscriminadamente incorporado pelo sujeito, mas depende da articulação com a atividade concreta desse sujeito. Assim, entre o artefato (ferramenta produzida pela cultura) e o instrumento há a atividade objetiva de cada indivíduo. Há a necessidade do uso, de esquemas de apropriação pessoal, há a manifestação da plenitude do sujeito em atividade ${ }^{6}$.

A informatização do processo judicial já é uma realidade imposta ao Judiciário brasileiro e obriga todos os servidores a utilizarem a nova ferramenta de trabalho. Dessa forma, surgem questionamentos importantes sobre essa mudança, como: carga de trabalho, capacidade da ferramenta e dificuldades geradas. Visto que ainda há pouca pesquisa investigando o tema, o trabalho realizado se propôs a compreender a visão dos trabalhadores sobre esse momento de transformação do processo de trabalho.

\section{Métodos}

Este estudo foi uma pesquisa de campo com abordagem qualitativa, entendida como aquela capaz de incorporar as questões do significado e do simbólico. Segundo Minayo ${ }^{10}$, "o universo das investigações qualitativas é o cotidiano e as experiências do senso comum, interpretadas e reinterpretadas pelos sujeitos que as vivenciam".

Utilizamos as representações dos trabalhadores, conforme abordado por Ferreira e Fernandes ${ }^{11}$, que tiveram como enfoque na condução de sua pesquisa a Ergonomia da Atividade Aplicada à Qualidade de Vida no Trabalho, conforme preconizado por Ferreira $^{12}$. Neste enfoque, com fundamentos conceituais do campo da teoria piagetiana de equilibração cognitiva, a ótica dos trabalhadores compreende as representações do mundo do trabalho elaboradas pelos sujeitos, sendo configuradas pelas redes de propriedades, de saberes, de conceitos, do saber-fazer, de crenças, de sensações vividas, de sentimentos de bem e mal-estar, de expectativas.

Os atributos basilares e interdependentes dessas representações são: (a) elas são resultado das vivências dos trabalhadores, ou seja, são construídas e selecionadas ao longo da história do sujeito; (b) elas constituem o processo orientador da atividade, em que o sujeito interage com o meio de trabalho intentando descrevê-lo e compreendê-lo, para assim agir sobre ele, utilizando-o e/ou transformando-o; uma dinâmica que provoca transformações no próprio sujeito ${ }^{11}$.

Este estudo contou como local da pesquisa um Tribunal Regional do Trabalho (TRT), que possui 158 varas do trabalho, totalizando 4.818 
trabalhadores - sendo 284 magistrados e 4.534 analistas e técnicos judiciários.

Os participantes da pesquisa foram servidores, técnicos e analistas judiciários, de sete varas do trabalho de dois municípios que já contam com o PJe em todas as suas fases há cerca de dois anos. A seleção dos participantes seguiu o critério de acessibilidade, tendo em vista a disponibilidade deles em conceder a entrevista, e também utilizou a indicação dos secretários das varas e gestores das unidades. O número de entrevistados seguiu o critério de saturação, considerando a diversidade e a intensidade das informações necessárias para o trabalho ${ }^{10}$, sendo o mínimo de dois servidores por vara.

As entrevistas semiestruturadas foram realizadas entre dezembro de 2014 a março de 2015, gravadas e transcritas para análise. O roteiro abordou aspectos da percepção do trabalho e as alterações vivenciadas no processo de trabalho e nas qualificações após a implementação do PJe.

Foi empregada a técnica de análise de conteúdo construtiva-interpretativa, conforme proposta por Gonzalez Rey ${ }^{13}$. O autor afirma que "o conhecimento não é uma soma de fatos definidos por constatações imediatas do momento empírico, mas seu caráter interpretativo é gerado pela necessidade de dar sentido a expressões do sujeito estudado"13. Essa forma de análise de conteúdo é aberta e processual, e não almeja reduzir o conteúdo a categorias concretas restritivas.

Foi também realizada a pesquisa documental, de textos e notícias contidos no site interno do Tribunal, bem como consulta ao material de formação utilizado pela Escola Judicial para treinamento do uso do sistema, com objetivo de conhecer as normas antecedentes da atividade estudada.

A abordagem ergológica escolhida como referencial teórico analítico prioriza o estudo das situações de trabalho considerando a existência de uma distância entre o trabalho prescrito e o trabalho real, conforme identificado pela ergonomia da atividade, grande influência em seus conceitos, em especial do médico e ergonomista Alain Wisner. Na perspectiva epistemológica, a ergologia privilegia o estudo das situações de trabalho fundamentado na dialética entre os saberes instituídos (prescrições e normas) e os saberes da experiência (singular da atividade concreta) ${ }^{5}$.

Segundo Schwartz ${ }^{14}$, "todo universo de atividade de trabalho é um universo onde reinam normas de todos os tipos: quer sejam científicas, técnicas, organizacionais, hierárquicas, quer remetam a relações de desigualdade, de subordinação, de poder". Essas normas e valores que orientam a atividade são constantemente reformulados e transgredidos diante de diferentes variabilidades. Dessa forma, toda vez que o homem entra em ação no trabalho, ele coloca em debate o que dele é exigido e o que ele exige de si mesmo, e então ingressa num debate de normas e de transgressões, o que, frequentemente, resulta em renormalizações e leva a compreender o trabalho como um uso de si, por si e pelos outros nos coletivos de trabalho, definidos pela ergologia como "dramáticas do uso de si”.

Sobre o tema das mudanças, Schwartz ${ }^{5}$ vai dizer que é o caráter sistêmico do seu impacto que é contestável: "as mudanças em curso não têm o mesmo significado para os indivíduos conforme sua história, sua vida pessoal; não têm tampouco a mesma significação para o mesmo indivíduo, segundo a evolução de sua vida. A mudança tem um custo e este custo não é o mesmo para todos". ${ }^{5}$

Cada um, individual ou coletivamente, reinventará localmente o emprego eficaz de um princípio técnico. Isso porque, como afirma Canguilhem ${ }^{15}$, há qualquer coisa que não é viver se nos assujeitamos às normas de um meio, pois todo homem deseja ser sujeito de suas próprias normas, sendo esse desejo algo vital. Como nos afirma Fígaro ${ }^{6}$, "entre o já prescrito (inscrito nos artefatos) e o uso específico, surge o novo, essa é a marca da atividade humana; é por meio desse movimento que se renovam os artefatos, incorporados como instrumentos".O projeto foi aprovado pelo Comitê de Ética em Pesquisa do Centro de Pesquisas René Rachou da Fundação Oswaldo Cruz em 05/11/2014 sob número CAAE 37358814.5.0000.5091.

\section{Resultados e Discussão}

Participaram 14 servidores: 9 eram técnicos judiciários e 5 analistas judiciários. Os magistrados procurados argumentaram não ter disponibilidade de tempo para conceder entrevista durante o período de realização da pesquisa. Há diferenciação entre magistrados e os demais servidores devido ao ingresso no serviço público através de concursos distintos, tendo uma grande diferença de autonomia em suas atuações. Também há diferenciação entre analistas e técnicos judiciários, que ingressam na carreira por concursos públicos diferentes e recebem distintas remunerações. Para os técnicos exige-se o ensino médio completo, e para os analistas, o ensino superior completo, porém, frequentemente, não há diferenciação das atividades executadas nas varas do trabalho, conforme observado no trabalho de campo. Apesar de não exigido, parece ser comum que os servidores técnicos tenham nível superior. Dos entrevistados neste trabalho, por exemplo, apenas 1 (um) não 
possuía esse nível de escolaridade. Entre os participantes, apenas os analistas exerciam cargo de gestor.

\section{Sentidos do trabalho}

O sentido do trabalho é permeado por diversos valores subjetivos, incluindo valores morais, que são formados social e historicamente. Nas entrevistas realizadas, o trabalho é visto como importante para os próprios trabalhadores e para a sociedade, sendo reconhecido como fonte de sustento, de sentido e de realização pessoal.

O trabalho na vida de qualquer um já é uma coisa muito importante, faz parte do ser humano mesmo, do seu crescimento pessoal, da sua relação com os seus colegas, então eu acho importantíssimo. Faz parte da minha vida mesmo. (E4)

O tribunal na minha vida tem uma repercussão muito grande, porque é daqui que eu tiro meu sustento, que eu sustento a minha família. (E2)

No último relato há uma associação direta do sentido do trabalho com a remuneração. Sabemos que o trabalho no nosso modelo produtivo não garante condições de produzir para si, mas dá condições de adquirir um salário para comprar o necessário à nossa sobrevivência ${ }^{16}$. Antunes ${ }^{17}$ pontua: "o que deveria se constituir na finalidade básica do ser social - a sua realização no e pelo trabalho - é pervertido e deturpado. O processo de trabalho se converte em meio de subsistência”. Especialmente no serviço público, muitas vezes a garantia de bom salário e a estabilidade financeira são os motivos de escolha e permanência na instituição. Desconsidera-se até a possibilidade de realização pessoal pelo trabalho, como se observa nas manifestações a seguir:

Agora, até a questão do trabalho você tem que fazer o que gosta. Até pelo concurso público a regra é que as pessoas fazem o concurso público basicamente por dois motivos... Querem a estabilidade e a aposentadoria. Eles visam a garantia, a estabilidade, e quando começam a executar as tarefas nem sempre gostam, mas também nunca pedem pra sair; é aquela questão de sobrevivência. (E8)

Por enquanto é a questão financeira. A questão de realização pessoal ainda não tem. (E13)

Por outro lado, o relato a seguir nos sugere que o acompanhamento do ciclo completo do ato de trabalho, no qual o trabalhador tem ciência de todas as etapas de produção e tem contato com o resultado final, seja fundamental para o reconhecimento de sua importância.

É muito importante porque eu percebo, pelo menos eu tenho pra mim que o que eu faço aqui tem um sentido, na medida em que começa um processo, a gente vê o processo judicial, a gente vê ele começar, vê ele ter uma decisão, a gente vê ele terminar, seja com um pagamento de quem quer que seja, ou seja arquivando o processo, isso me satisfaz porque eu vejo que meu trabalho tem um resultado, eu vejo resultado do meu trabalho. (E1)

Para nossos entrevistados, o significado do trabalho tem forte relação com seu papel social. Eles ressaltam a relevância de ser servidor público e, ainda, de trabalhar com o acesso à Justiça.

\begin{abstract}
Significa muito. Nesses quatro anos e meio, quase cinco anos que eu estou como servidor público, eu venho aprendendo o que significa ser servidor público, que significa na verdade servir ao público, e a importância desse serviço, de dar um serviço adequado, um serviço de qualidade às pessoas lá fora. (E6)

E para a sociedade, mais ainda, porque o trabalhador que é a parte mais fraca na relação que ele tem com o empregador. Se o empregador, espontaneamente, descumpre as cláusulas do contrato de trabalho, a legislação trabalhista, o único lugar que a pessoa tem pra se socorrer é aqui. Se não for aqui, ele vai ficar sem receber, porque ele não tem como obrigar o empregador, que é a parte mais forte economicamente, de pagá-lo, então ele tem que buscar a Justiça para poder ter essa reparação. (E1)
\end{abstract}

Segundo a teoria marxista, as relações de trabalho se estabelecem a partir da exploração do homem pelo próprio homem. Porém, essa interação entre capital e trabalho não é estática, desenrola-se constantemente sob novas condições e evidencia a existência de um terreno da luta de classes constantemente renovado ${ }^{16}$.

Nesse sentido, Schwartz ${ }^{5}$ também afirma que uma situação de trabalho contém as questões da sociedade. A perspectiva ergológica nos impele a unir permanentemente o micro e o macro, uma vez que ela ressalta o fato de que toda atividade, incluindo a de trabalho, encontra debates de normas e, em consequência, escolhas, que se fundam em encontros de valores.

Especialmente no âmbito da Justiça do Trabalho, a consideração do macrocontexto socioeconômico e cultural permeia as decisões tomadas no microcontexto das atividades. Suas tarefas consistem fundamentalmente em auxiliar as decisões jurídicas que reparam trabalhadores desfavorecidos pela forma de estruturação da divisão social do trabalho e das disputas de poder presentes no sistema capitalista de produção.

Quanto mais ágil você é, mais o processo corre rápido e ajuda a parte, às vezes, a receber os valores... É muito importante. (E12) 
A celeridade citada, que inclusive está presente na missão e visão do órgão campo desta pesquisa, implica nos servidores e magistrados certo grau de "aceleração" de suas tarefas, reforçada pelo compromisso com suas atividades de promoção do bem comum da coletividade.

Esse tribunal é inclusive reconhecido por números que o colocam acima da média nacional no que diz respeito ao desempenho do Judiciário trabalhista, já considerado o mais ágil do país. A celeridade é então cobrada hierarquicamente por todos os níveis, passando dos órgãos superiores (Conselho Superior da Justiça do Trabalho e Conselho Nacional de Justiça) à presidência e diretoria-geral, destas a magistrados e gestores, e, por fim, destes aos demais servidores.

Ferreira e Fernandes ${ }^{11}$, ao estudarem a qualidade de vida no trabalho em órgão do Poder Judiciário brasileiro, observaram que a pressão excessiva por produção, com vistas à celeridade necessária nos processos associada a uma sobrecarga de atividades com volume cumulativo de trabalho, era fator causador de mal-estar no trabalho.

\section{O trabalho prescrito: processo de trabalho}

Quando alguém exerce o direito de ação (ou seja, "processa" o outro), exerce tal direito perante o Judiciário, que é o poder estatal especializado no atendimento desta demanda social. Na prática, este direito de ação exercido se materializa em uma pasta, cheia de folhas, ou até de vários volumes. Também é chamado de "processo" ou autos: um conjunto de peças processuais, produzidas pelas partes, servidores, magistrados e outros ${ }^{18}$.

Eu sou nova no Tribunal, cheguei quase junto com o PJe, então para mim foi ótimo. Eu recebi muito bem: não ter mais que carregar processo, cheirar ou respirar ácaro; é bom demais. (E7)

O PJe modificou a realidade. Os autos que costumava folhear passaram a ser eletrônicos e somente podem ser acessados via computador, desde que este esteja conectado à Internet.

O sistema processual foi projetado para que cada ação sempre "caminhe" adiante em busca do seu destino (a solução do conflito). O PJe não altera o caminho (fluxo) do processo de trabalho, nem revoga as normas processuais constitucionais e infraconstitucionais: apenas modifica a maneira como é realizado o trabalho.

Ao longo do fluxo do processo, algumas situações fazem a ação parar e aguardar que o servidor selecione qual caminho será tomado para o processo prosseguir. Essas decisões, tomadas pelos servidores, serão resultado de diretrizes de funcionamento da Secretaria da Vara, passadas pelo magistrado, de acordo com suas posições jurídicas ${ }^{18}$.

Gomes Júnior, Brandão e Lopes ${ }^{19}$ descrevem as atividades exercidas nas secretarias de varas do trabalho, que têm início quando as petições, instrumento pelo qual o interessado invoca a atividade jurisdicional, são distribuídas para as varas pelo setor de distribuição. Este setor impacta o trabalho, pois a distribuição das petições, sendo feita aleatoriamente, não leva em consideração o número de processos em andamento em cada unidade.

Após a distribuição, ocorre a autuação do processo, que consiste em receber um requerimento que contenha uma decisão administrativa e prepará-lo para a tramitação interna. A reclamada será citada ou notificada para comparecer à audiência e apresentar a defesa. O advogado apresenta a defesa, e é marcada a audiência inicial.

Durante a audiência, depois de qualificadas as partes e apurados todos os presentes, o juiz deve sugerir a conciliação do litígio. Após essa etapa, não ocorrendo acordo, a reclamada deve apresentar a sua contestação, de forma escrita ou oral. A defesa só pode ser apresentada após a proposta de conciliação e a contestação é necessariamente acompanhada dos documentos pertinentes (artigo 467 da CLT $^{20}$ ).

No fim da audiência, o juiz definirá a audiência de instrução, sendo as partes desde então intimadas. Também determinará o prazo para o reclamante se manifestar em réplica aos argumentos da contestação da reclamada e aos documentos juntados.

O despacho é a decisão administrativa sobre o pedido inicial. Os servidores da Secretaria de Vara elaboram esses despachos e os encaminham para apreciação do juiz. Se o magistrado estiver de acordo, ele assina e prossegue o processo. Caso contrário, o despacho é mandado de volta para a secretaria fazer as alterações necessárias. Para elaborar o despacho, o servidor deve levar em consideração o perfil do juiz e o modo como este costuma julgar os processos. Além disso, o servidor deve ser preciso e atinente à matéria do processo conforme definido por lei.

Após o despacho e a publicação, últimas etapas do acompanhamento, o processo é encaminhado ao arquivo. A unidade que encaminhar o processo ao arquivo fará as verificações e a última informação, colocando a expressão "arquive-se", acompanhada do tipo de despacho recebido, de data, carimbo e assinatura da chefia (secretário da vara) ou de pessoa com nível hierárquico igual ou superior ${ }^{19}$.

Para Bourdieu ${ }^{21}$, "o direito está inserido dentro do campo jurídico com toda a sua lógica interna, onde se busca de forma permanente o acúmulo de 
capital jurídico que implica em legitimar os valores inerentes aos conflitos com regras fundadas no formalismo".

A primeira competência eu acho que é conhecer direito do trabalho e direito processual do trabalho a fundo. Quanto mais a pessoa conhece, melhor é a tramitação dos processos. (E1)

A fala da entrevistada evidencia que o engajamento com o trabalho, na busca de melhor tramitação do processo, exige conhecimento jurídico e processual.

As disputas presentes no meio jurídico se assentam na separação entre aqueles que são profissionais e os não profissionais, construindo uma fronteira entre os que fazem parte desse campo e os excluídos dele ${ }^{21}$. Bourdieu ${ }^{21}$, ao refletir sobre o poder no campo jurídico, afirma:

O desvio entre a visão vulgar daquele que se vai tornar "justiciável", quer dizer, num cliente, e a visão científica do perito, juiz, advogado, conselheiro jurídico, etc., nada tem de acidental; ele é constitutivo de uma relação de poder ${ }^{21}$.

No campo jurídico, há um monopólio do uso do Direito, com base num formalismo construído por agentes e instituições jurídicas. Toda a legitimação das decisões se fundamenta na convicção de sua universalidade, neutralidade e justiça ${ }^{22}$.

Essa legitimação de poder também exige que se mantenha desconhecido seu funcionamento, reafirmando setores dominantes, fundamentado na naturalização de práticas e regras. Nesse sentido, a presença do ritual no campo jurídico funciona como um marcador da separação social dos pertencentes ao campo, que reforça a ordem estabelecida, autoriza a delegação de representatividade do coletivo e desencoraja qualquer transgressão da ordem ${ }^{23}$.

Segundo Madeira ${ }^{22}$, o entendimento de Bourdieu é que "as regras que aparecem como neutras e necessárias à administração da justiça contribuem para que o campo permaneça estável quanto às distribuições de poder em seu interior”. Em análise, Bourdieu vê o Direito como uma forma de violência simbólica, permitindo a legitimação de práticas de dominação e violência, convenientes e necessárias à manutenção de um status quo 22 .

\section{Implementação da nova tecnologia: o PJe}

Para o indivíduo cujo trabalho é subitamente modificado, a revolução técnica manifesta-se como um outro, ameaçador ${ }^{24}$. Porém, a percepção da chegada deste outro se apresentou de forma variada entre nossos entrevistados, indicando que essa percepção é individual, apesar de carregada de valores coletivos.
E agora vem o PJe, e a gente fica assim mais assustado. Todo início do desconhecido a gente sente medo, a gente tem dificuldade, mas a gente tem que procurar vencer isso, enfrentando e procurando mesmo aprender, e é errando que a gente aprende. (E2)

Eu adorei porque eu gosto dessas coisas de computador, de tecnologia... Eu acho que vem sempre pra acrescentar e pra melhorar, então eu gostei, não tive resistência nenhuma não. (E13)

Inclui-se, como fator importante dessa primeira interpretação sobre a mudança, a própria experiência de vida dos indivíduos, chamando atenção para a relação prévia com instrumentos tecnológicos.

A inclusão de novas técnicas e tecnologias no trabalho, como a Internet, possui intenções de transformação. Utilizar uma técnica supõe, por um lado, seguir operações predefinidas e, por outro, uma certa reinvenção local ${ }^{25}$. Essa reinvenção é a expressão da subjetividade do trabalhador, que traz sua experiência e história de vida para dialogar com as técnicas propostas, talvez, isso explique as diferentes formas de enfrentamento dessa nova realidade.

\begin{abstract}
Eu preciso ter mais atenção, eu passei a usar colírio porque meus olhos começaram a ficar muito vermelhos, o cansaço físico é maior porque fico mais tempo sentada; no físico, você vai buscar o $2^{\circ}$ volume, o $3^{\circ}$ volume, vai pegar o papel na impressora, então isso te faz levantar mais. No PJe não, você fica ali o tempo todo, quando você nota já está há quase duas horas sentado, então isso mudou muito a minha vida. (E2)

Hoje eu acho que foi para melhor, o funcionamento da Vara como um todo. Como aqui é uma Vara muito antiga, são muitos processos, então a gente perdia muito tempo procurando processo, colocando processo no lugar... Essa questão da autuação... numera, carimba, fura; se perde muito tempo com essas atividades. (E13)
\end{abstract}

Marx ${ }^{3}$ já colocava que as máquinas são o meio mais poderoso para aumentar a produtividade do trabalho e, assim, para prolongar a jornada de trabalho além dos limites estabelecidos pela natureza humana. Porém, visto que o prolongamento da jornada é legalmente limitado, assume decisiva importância o fenômeno da intensificação do trabalho, no qual se aumenta naturalmente a velocidade do trabalho e, em consequência, sua intensidade ${ }^{3}$.

Pode, porque é um pouco viciante. Você tem um controle melhor do seu trabalho porque você vê os numerozinhos lá... "Tem tantos processos pra fazer tal tarefa...", então acaba que você fica querendo, principalmente quem é ansiosa como eu, fica querendo resolver aquilo, fica querendo diminuir aqueles números. (E13)

A colocação da entrevistada, que identifica sua ansiedade como regulador do seu envolvimento com 
a resolução das tarefas, nos explicita as dinâmicas do uso de si por si e pelos outros. Schwartz ${ }^{26}$ também vai dizer:

Carga de trabalho e fadiga deixam de ser dados objetivos que agridem do exterior o indivíduo; eles se negociam onde tudo depende da maneira pela qual o indivíduo, nas suas singularidades e limites, encontra o objetivo a realizar como ponto de apoio ou, ao contrário, como restrição de seus possíveis particulares ${ }^{26}$.

Porém, a nova ferramenta de trabalho do Judiciário, sendo um sistema ligado à rede mundial de computadores (web), permite o acesso remoto a qualquer tempo e hora, criando para os trabalhadores uma nova relação com a organização do tempo da jornada de trabalho. Importante considerar isso em associação com a já identificada noção de celeridade incorporada pelos participantes da nossa pesquisa.

\begin{abstract}
Eu acho que o PJe deveria ter um horário de encerramento, porque não tem um horário de parar, todo dia que você vai lá tem 20 petições, e isso numa única das dezenas de caixas que você tem de olhar; então, nesse sentido, eu acho que aumentou muito pra gente, porque não tem hora aqui; aqui você encerra o expediente... Aí você vê nas petições, você pensa: o rapaz podia estar fazendo uma coisa mais interessante, tá peticionando meia-noite, duas horas da manhã e, aí, realmente, acresce demais o serviço. (E10)
\end{abstract}

Observamos uma nova realidade de trabalho marcada pela flexibilização da jornada, na qual se torna difícil distinguir o tempo de trabalho do tempo da produção ou do tempo livre.

Somado a isso, temos um real aumento da demanda processual no contexto de todo o sistema Judiciário brasileiro, em especial na Justiça Trabalhista. Para a desembargadora Cleusa Regina Halfen, presidente do TRT-RS, esse crescimento do número de processos pode se referir não apenas ao descumprimento da lei por parte das empresas e patrões, mas também a uma grande rotatividade no mercado de trabalho: "Quanto maior o número de rescisões contratuais no mercado, mais ações trabalhistas". De acordo com a desembargadora, a maior acessibilidade do Judiciário, causada pela implantação do PJe, atendeu parte de uma demanda reprimida, o que também gera acréscimo percentual ${ }^{27}$.

Sendo assim, na opinião de Schwartz ${ }^{5}$, um dos grandes problemas na introdução de novas tecnologias encontra-se nas condições sociais dessas mudanças. Toda mudança tecnológica tem efeitos sobre as qualificações, sobre o emprego, sobre o plano de cargos e salários, sobre o nível dos efetivos, sobre uma série de coisas que não são no início necessariamente pensadas, nem mesmo discutidas. Se não há negociação sobre as repercussões, sobre as consequências sociais da introdução dessas tecnologias, de imediato se encontram problemas para efetivar as mudanças. Não se pode dizer que as pessoas em situação de trabalho se recusam a mudar, o problema é o modo como a mudança é conduzida, as condições nas quais ela deve se realizar.

Os servidores entrevistados se ressentem da ausência de consulta aos trabalhadores sobre seus conhecimentos e experiências prévias, anteriormente à implementação. Além disso, reforçam a percepção de que os responsáveis pela criação do sistema não conhecem o trabalho a ser executado pelos usuários do PJe, visto que a criação e implementação do sistema é gerenciada por um Comitê Gestor do PJe da Justiça do Trabalho, centralizado no Conselho Superior da Justiça do Trabalho. Cada tribunal conta com seu Comitê Gestor Regional, que busca aproximar as partes envolvidas, porém a participação dos servidores é limitada ao envio de propostas, que são analisadas por diversas instâncias antes de se efetivarem modificações.

E a gente sempre tenta, a gente troca ideia com o pessoal da diretoria de PJe; a gente sempre tem acesso, eles nos ajudam muito também, mas não é uma coisa direta, com quem elabora o programa, com quem muda, com quem coloca a versão, com quem fez; é tudo muito centralizado. (E5)

É um projeto nacional, então qualquer mudança, para mim, torna-se mais difícil, mas o que eu percebo é que quem está trabalhando no PJe, na criação do PJe, são pessoas; essa desvinculação com o usuário, com a prática. (E8)

Ao tratar do tema da mundialização, Schwartz ${ }^{28}$ afirma: "essa combinação entre colocar em crescente 'penumbra' o trabalho e o afastamento das instâncias de decisão estratégica sobre ele está a produzir um mal-estar multiforme cuja explicação histórica não é possível ignorar".

Somado à percepção de insuficiente participação dos executores do trabalho na formulação e implementação do sistema, temos muitas dificuldades relatadas com a sua operacionalização.

Com o processo virtual você trabalha muito mais, você requer muito mais atenção, seu erro fica muito mais visível para o público externo, então você tem uma cobrança muito grande. (E2)

A dificuldade do PJe é pelo fato de você poder só abrir
uma página de cada vez e o tempo que ela demora
pra abrir, pra ela fechar, pra assinar, pra digitalizar,
é o tempo que você gasta, e você folhear, você marcar
onde você quer, o que você quer, é muito mais fácil no
físico do que no PJe. (E2)

As principais dificuldades relatadas incluem a lentidão do sistema, a dificuldade na leitura das 
peças, o excesso de "cliques" no mouse, a impossibilidade de enviar para assinatura do juiz mais de um documento ao mesmo tempo, a maior visibilidade dos erros e o layout "carregado" da página. Consideramos que a lentidão é o principal fator gerador de estresse no trabalho com o novo sistema, haja vista a cobrança de celeridade que as normas impõem aos servidores.

Ao investigar os impactos de novas tecnologias na sociabilidade e no savoir-faire de trabalhadores, Assis ${ }^{29}$ encontra: maior concentração/atenção solicitada ao trabalhador; modificações no ritmo de trabalho; mudanças na capacidade de autodeterminação das tarefas; mudanças no processo de comunicação e no modelo de trabalho coletivo; mudanças em relação às exigências; mudanças quanto ao grau de envolvimento e participação dos trabalhadores; mudanças na prescrição das atividades; mudanças no processo de qualificação e no savoir-faire dos trabalhadores e mudanças nos mecanismos de controle.

\begin{abstract}
A gente não pode continuar trabalhando com a conformação de uma secretaria para processo físico quando não é mais processo físico [...] Então eu acho que precisamos hoje é de servidores muito qualificados, porque não tem mais espaço para um servidor que não saiba mais ou fazer um despacho ou cumprir um despacho [...] Hoje a gente precisa de pessoas mais capacitadas, e de mais pessoas. Porque como o sistema é mais demorado para você trabalhar, você não consegue trabalhar com o número de pessoas que você teria na Secretaria. (E1)
\end{abstract}

O PJe exige que você tenha um conhecimento mínimo, básico, pré-existente de informática; um conhecimento básico. Senão você vai ter muita dificuldade. Então, para realizar as intimações, por exemplo, no sistema, você além de conhecer o sistema, você tem que conhecer um pouco de informática também, que isso vai te dar mais facilidade, porque senão você vai ter muita dificuldade e não vai render o trabalho. (E6)

Pelo relato dos entrevistados, fica clara a exigência de novas e maiores qualificações.

\section{Qualificações e competências}

As novas exigências impostas aos trabalhadores em razão do uso de novas técnicas para execução do seu trabalho colocam em questão a dificuldade acerca da determinação das competências para o trabalho, bem como as estratégias de formação.

Quando questionados sobre o treinamento oferecido pelo Tribunal para o uso do sistema do PJe os entrevistados relataram, de forma recorrente, sua insatisfação.

O treinamento foi muito rápido, insuficiente...; foi mais um panorama, um retrato do sistema. Eu acredito que tudo tenha sido aprendido com a prática.
O treinamento foram só ideias do funcionamento, os caminhos, para você conhecer o sistema, mas assim a prática, foi a prática que nos ensinou. (E5)

Fica evidente que o aprendizado no trabalho não se dá de forma efetiva considerando-se apenas o ambiente formal de aprendizado. Pelo contrário, a prática cotidiana se mostra muito mais capaz de colocar as pessoas aptas a realizarem suas atividades.

Olha, o treinamento, a gente sabe que é difícil ter um treinamento para um sistema grande como esse; um treinamento relâmpago... [Risos]. A gente sabe que o negócio é fazendo mesmo! Então eu acho que não é tanto esticar o período de treinamento, mas é ter um maior tempo para as pessoas se adaptarem a isso, para as pessoas poderem treinar até por conta própria. (E5)

O entrevistado demonstra conhecer a dificuldade na verbalização da atividade de trabalho, problema largamente ignorado ou subestimado. Com vistas à grandeza do sistema e à variabilidade das situações em atividade, demanda-se uma mistura de saberes já armazenados, configurando um polo atemporal, e de competências criadas e retrabalhadas em atividade, configurando o polo do histórico. Assim, acreditamos ser necessária neste contexto, assim como no exercício de todo ofício, a capacidade de aproveitar a oportunidade favorável (o kairós) para desempenhar perfeitamente sua tarefa, algo de certo desenvolvido apenas na experiência prática ${ }^{30}$.

Kairós fala de um certo tipo de inteligência que permite que a ação humana aconteça em condições sempre e infinitamente variadas. Essa inteligência do kairós, bastante impalpável, trata de uma relação entre o saber e o tempo, e não pode ser ignorada ao abordar as competências. Essas, por sinal, difíceis de caracterizar, dado que incluem ingredientes heterogêneos em certo equilíbrio, que respondem à constante variabilidade das atividades ${ }^{30}$.

Importa-nos determinar a competência industriosa, noção elaborada por Schwartz ${ }^{5}$, que é uma combinação complexa de ingredientes que não podem ser nem ensinados, nem avaliados em formato único. Inclui o domínio dos protocolos em suas antecipações, o que se realiza de fato em atividade, em suas singularidades, e a gestão do encontro das dimensões anteriores, feita com base nos valores. Torna, então, especialmente delicado, pois inclui uma dimensão de valor, e não há nenhuma escala absoluta de avaliação de valores ${ }^{31}$.

Schwartz ${ }^{31}$ tenta então decompor essa diversidade de ingredientes, sob abordagem ergológica, com intuito de melhor compreender os sentidos atribuídos a cada um deles, possibilitando entrever articulações e interações entre eles, os quais passamos a aplicar em nossa análise. 
O primeiro ingrediente da competência industriosa trata da situação que se passa em conformidade com um protocolo experimental, do que é antecipável e prescrito. Esse ingrediente assume conteúdos diversos conforme as situações, os tipos de atividade, ou os níveis hierárquicos, mas não denota grande dificuldade para se identificar. Abarca as normas antecedentes, os conceitos, as leis e regulamentos, a técnica, as condições de trabalho; e diz respeito aos saberes identificáveis e acumulados previamente.

Para apreendê-lo, submete-se às normas e imposições internas, sendo sempre objeto de aprendizado progressivo. Ao trabalhador pede-se aparente "esquecimento" de sua experiência para melhor acesso à relativa generalidade do conceito.

Isso eu acho até que é uma questão de adaptação, eu não ponho isso na culpa do sistema ser ruim. Porque a gente acostumou, durante muitos anos, pelo menos no meu caso aqui, durante 16 anos a lidar com processo físico apenas, então a gente tem traquejo para mexer com isso, e tem só dois anos que eu mexo com PJe. Então essa questão de leitura de peças e tal, isso é uma questão de adaptação. (E1)

O segundo ingrediente encontra-se num polo oposto. Trata de ressingularização em relação às normas antecedentes, aquelas prescritas previamente, e ser competente nesse caso, diferente do primeiro ingrediente, corresponde a estar imerso nessa historicidade e ter a capacidade de decidir, de arbitrar, considerando os contextos e conjunturas. "Saberfazer”, saberes investidos/gerados na atividade não podem, por definição, ser ensinados, verbalizados, nem avaliados em concordância com a "disciplina", somente se formam através da própria operatividade e, portanto, não se incorporam no instante.

Eu aprendi na prática. Isso não é ensinado, o serviço é tão específico que na faculdade a gente não aprende isso, obviamente a gente aprende a questão mais ampla, os princípios, a legislação aplicável etc. E o Tribunal também nunca cuidou, pelo menos no início, de promover qualquer tipo de treinamento, isso foi no dia a dia mesmo, na prática diária. (E1)

Pode-se definir o terceiro ingrediente da competência como a capacidade de se estabelecer uma dialética entre o primeiro e o segundo ingredientes. É a articulação entre o polo conceitual e o polo das experiências no ato de trabalho, podendo ser nomeado "agir competente" 2 .

A elaboração de uma dialética inteligente fornece uma gama de possibilidades, assim, trata-se de um verdadeiro trabalho, um exigente "uso de si por si", em que a história enriquece os saberes, remodifica as normas e concede indivíduos sempre ressingularizados pela vida.
Às vezes a gente vai aprendendo, é ali, quando surge uma situação de determinado processo que você vai vendo qual caminho tomar. (E14)

Posto que nosso referencial ergológico traz o conceito do uso de si no trabalho, considerando a atividade como espaço dessas dramáticas, surge a evidência do vínculo inegável entre as competências e os valores implicados na atividade.

Chegamos então ao quarto ingrediente, que trata do debate de valores que perpassa toda atividade de trabalho e que vai orientar as escolhas conscientes e inconscientes. Esse ingrediente introduz um problema com relação à objetividade e neutralidade na avaliação das competências, uma vez que não é possível julgar os valores dos outros de forma independente à sua experiência histórica.

Tratando do ponto positivo do quarto ingrediente, devemos incentivar sua manifestação, criar oportunidades para debater dinâmicas e limitações presentes nos meios de trabalho. Com isso levanta-se o problema da inconstância das políticas gerenciais, por mudanças constantes de interlocutores e arquiteturas organizacionais, que resultam em dificuldades na constituição de "organizações vivas do trabalho" e na implantação de um debate sobre os vínculos entre os valores e as atividades concretas. Este é o caso do tribunal, campo desta pesquisa, onde a administração é substituída a cada dois anos, eleita em votação pelo Tribunal Pleno, formado pelos desembargadores do órgão.

Ao falar do quinto ingrediente, Schwartz ${ }^{31}$ introduz a reflexão sobre a recorrência parcial do quarto ingrediente em todos os outros. Nessa interlocução entre os ingredientes, o encontro tratado no segundo ingrediente, marcado pelas singularidades e historicidade, será mais bem incorporado caso se consiga nele inscrever patrimônios, que os saberes do trabalhador adquiram valor "patrimonial como campo pertinente de sua atividade e de sua vida"31. Dessa forma, o quinto ingrediente nos diz sobre a relação com o saber, sobre o interesse e busca de cada trabalhador em se aperfeiçoar, em buscar um aprendizado permanente, além das possibilidades dadas institucionalmente e pela organização do trabalho para que ocorra esse aprendizado.

Minha perspectiva é ter um tempo até para poder estudar, me atualizar, voltar a estudar, e não é o que acontece aqui, porque [com] a sobrecarga de trabalho aqui a gente não tem esse tempo. (E5)

Nossas entrevistas trazem relatos de incompatibilidade entre a carga de trabalho e a participação em estudos, delineando a sobrecarga de trabalho como fator limitador no desenvolvimento do quinto ingrediente. 
Por fim, o sexto ingrediente traz a noção de competência coletiva, que Schwartz ${ }^{31}$ prefere chamar de "qualidade ou construção sinérgica". Tendo em mente a impossibilidade de sermos competentes de modo igual em todos os registros, a ideia de equipe se mostra cada vez mais considerada e necessária. Assim, a noção de eficiência revela-se um produto coletivo.

Eu acredito que independente se a pessoa despacha, se a pessoa cumpre, ou se é servidor de Secretaria cada um tem sua importância. O juiz não consegue fazer tudo sem o servidor, e da mesma forma os servidores, muitos [deles], não conseguiriam fazer tudo; todo mundo precisa de todo mundo, então todo mundo tem a sua importância, e juntos como equipe é que a gente verdadeiramente consegue realizar esse serviço público, que outrora eu tinha falado, eficaz, com qualidade. (E6)

Porém, há uma impossibilidade em delinear coletivos estáveis e circunscritos, sempre nos deparamos com entidades coletivas relativamente pertinentes, não sendo possível identificar provas estáveis para "essa enigmática 'competência coletiva”. Schwartz ${ }^{32}$ explica:

\begin{abstract}
São entidades porque não seguem as fronteiras do organograma, nem mesmo os limites de uma empresa; são coletivas porque compartilham debates, negociações, valores e a tarefa de realizar renormatizações e não apenas regulações; e, por fim, são relativamente pertinentes porque os limites de sua abrangência são variáveis, levando em conta o foco ou o problema situado que se precisa enfrentar. As fronteiras mudam segundo as pessoas e suas atividades.
\end{abstract}

Esse "pensar de modo coletivo" sempre engloba escolhas e predisposições individuais. No sentido da capacidade para o trabalho em equipe, sob as mesmas condições, indivíduos diferentes exibirão disposições diversas ${ }^{31}$. Também é ressaltado por Schwartz ${ }^{31}$ que "essas qualidades sinérgicas não são um simples traço de caráter”, mas que as questões do "meio", como as políticas de governo do trabalho e o modo como os gestores lidarão com as questões do trabalho coletivo, são predominantes.

Concluindo, dada a grande variabilidade desses ingredientes em cada espectro pessoal, as sinergias verdadeiramente bem-sucedidas presumem um equilíbrio favorável dos ingredientes, de forma individual e, sobretudo, coletivamente ${ }^{31}$. Nossos resultados deixam claro que o aprendizado com os colegas é apontado como a principal fonte de capacitação para o trabalho desenvolvido nas varas, exemplificando como o coletivo pode se articular em função dos objetivos comuns do trabalho.

\begin{abstract}
Eu aprendi inicialmente...; houve um treinamento que o Tribunal ofereceu, porém esse treinamento foi muito simples. Foi algo mais inicial. Em seguida, eu fui ensinado mesmo por meus colegas de trabalho. Eles que paravam o trabalho deles para me ensinar o que eu deveria aprender naquele momento, e assim eu fui aprendendo. Hoje eu até ensino outros servidores mais novos. (E6)
\end{abstract}

Nesse sentido, temos os resultados do mapeamento das sete competências que melhor traduzem a estratégia, a missão, a visão e os valores do Tribunal e que foram escolhidas por 986 magistrados e servidores, representando $22 \%$ do TRT estudado, através de consulta realizada pela Secretaria de Desenvolvimento de Pessoas, em 2015 (Figura 1).

Nota-se que em primeiro lugar foi escolhido a cooperação e trabalho em equipe, que pode ser associada ao sexto ingrediente descrito por Schwartz ${ }^{31}$. Em segundo lugar, a aprendizagem contínua e autodesenvolvimento, que parece estar associada a todos os outros ingredientes, pois envolvem conhecimentos ligados ao primeiro ingrediente e ao segundo ingrediente, à dialética entre eles e à capacidade de fazer com que esses saberes adquiram valor patrimonial. A pesquisa demonstrou qual é o entendimento desses trabalhadores quanto à hierarquia de importância dada às competências específicas.

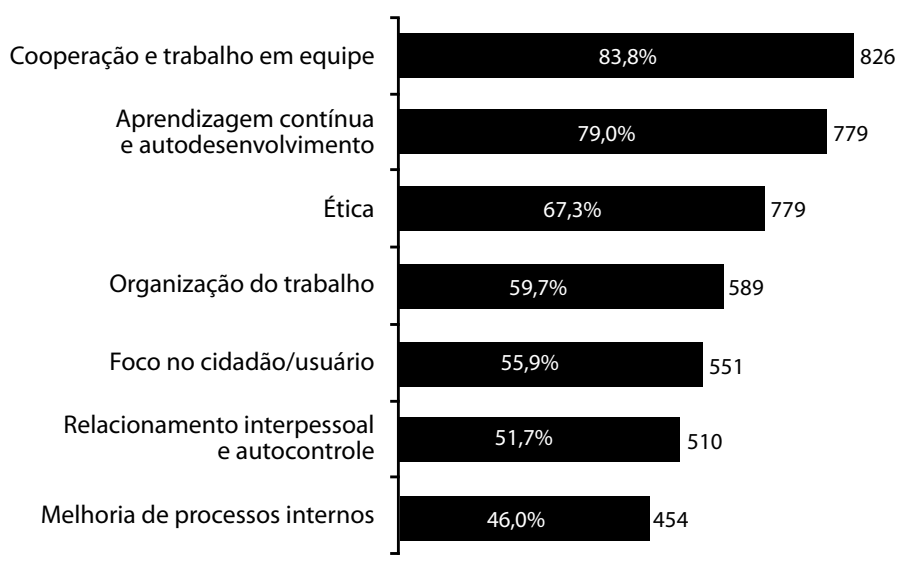

Figura 1 Mapeamento de competências realizada em um Tribunal Regional do Trabalho (TRT) em 2015 Fonte: Intranet TRT, $2015^{33}$ 


\section{Considerações finais}

Esta pesquisa teve como objetivo compreender a visão dos trabalhadores da Justiça do Trabalho sobre a transformação do processo de trabalho gerada pela implementação do PJe.

A introdução de novas tecnologias no meio de trabalho traz sempre intenções de transformação. Mas é importante lembrar que os trabalhadores tiram partido dessas técnicas graças ao seu poder de reinventá-las e, nesse movimento, renovam-se os artefatos e instrumentos de trabalho.

Percebemos que há uma relação entre essa resistência à mudança e a questão da subjetividade. Ao recusar a mudança, assume-se uma posição. Exprime-se de certo modo a vontade de não se submeter à mudança, mas de ser ator dessa mudança, não se deixar levar passivamente pelas transformações em curso. Apropriar-se da mudança é inseri-la na história, e isso é fundamental. Na impossibilidade de estabelecer um vínculo entre a nova técnica e o patrimônio de conhecimentos, de saber-fazer, de valores anteriormente adquiridos, a apropriação torna-se extremamente difícil.

Nesse contexto, encontramos que a implementação da tecnologia deve ser avaliada a partir do ponto de vista de quem a utiliza, considerando que houve custos pessoais e sociais acarretados por tal mudança, em particular as demandas impostas aos trabalhadores, considerando a necessidade de novas capacitações. Os entrevistados explicitaram desconforto com a ausência de consulta prévia e com o treinamento insuficiente para o uso da ferramenta. Destacam a sensação de aumento da demanda, também correlacionado com o alto envolvimento e comprometimento com o trabalho.

Novos estudos devem associar as entrevistas com observação e acompanhamento das atividades a uma análise mais aprofundada de documentos institucionais.

\section{Contribuições de autoria}

Fonseca FF foi responsável pela construção do projeto, realização da pesquisa, consolidação dos resultados e elaboração do relatório final; Cunha DM e Vieira EAO, pela discussão dos resultados e pela elaboração do manuscrito e aprovação da versão final; Modena CM, por orientar todo o processo de realização da pesquisa original, redação do manuscrito e aprovação da versão final.

\section{Referências}

1. Ribeiro ACA, Mattos BM, Antonelli CS, Canêo LC, Goulart Júnior E. Resiliência no trabalho contemporâneo: promoção e/ou desgaste da saúde mental. Psicol Estud. 2011 out/dez;16(4):623-33.

2. Trajano ARC, Cunha DM. Processo de trabalho no SAMU e humanização do SUS do ponto de vista da atividade. Trab Educ Saúde. 2011;9 Suppl 1:11336.

3. Marx K. O capital. Livro 1. O processo de produção do capital. 9. ed. São Paulo: Difel; 1984. 579 p.

4. Trinquet P. Prévenir les dégâts du travail: l'ergoprévention. Paris: PUF; 2009. 211 p.

5. Schwartz Y, Durrive L, organizadores. Tradução Jussara Brito e Milton Athayde. Trabalho e ergologia: conversas sobre a atividade humana. Niterói: EdUFF; 2007. 308 p.

6. Fígaro R. Comunicação e trabalho para mudanças na perspectiva sociotécnica. Rev USP. 2010 jun/ ago;86:96-107.

7. Cordeiro WM. Da reformulação do conceito de autos processuais no ambiente do processo eletrônico e suas consequências jurídicas. Rev Tribunal Regional Trabalho $13^{\mathrm{a}}$ Região. 2009;16(1):13-27.
8. Santos MA, Reis SC. Breves reflexões sobre o Processo Eletrônico no TRT da $13^{\mathrm{a}}$ Região. Âmbito Jurídico [Internet]. 2011 set;92. Disponível em: http:// www.ambitojuridico.com.br/site/index.php?artigo_ id $=10361 \& n \_l i n k=$ revista_artigos_leitura

9. Merlo ARC, Souza Filho GA, Dornelles RAN. Avaliação das condições de trabalho e de saúde dos servidores do Judiciário Federal no Rio Grande do Sul. Relatório de pesquisa. Porto Alegre: Instituto de Psicologia, Laboratório de Psicodinâmica do Trabalho; 2012.

10. Minayo MCS. O desafio do conhecimento: pesquisa qualitativa em saúde. 13. ed. São Paulo: Hucitec; 2013. 407 p.

11. Ferreira MC, Fernandes LC. Sobrecarga, cobrança, pressão...: a qualidade de vida no trabalho subtraída no contexto do Poder Judiciário brasileiro. In: Araujó JNG, Ferreira MC, Almeida CP, organizadores. Trabalho e saúde: cenários impasses e alternativas no contexto brasileiro. 1. ed. São Paulo: Opção; 2015. p. 13-31.

12. Ferreira MC. Qualidade de vida no trabalho: uma abordagem centrada no olhar dos trabalhadores. 2 . ed. Brasília: Paralelo; 2012. 341 p. 
13. Gonzalez Rey FL. Pesquisa qualitativa em psicologia: caminhos e desafios. Tradução Marcel Aristides Ferrada Silva. São Paulo: Pioneira Thomson Learning; 2005. 188 p.

14. Schwartz Y. Trabalho e uso de si. Pro-Posições. 2000;1(5):34-50.

15. Canguilhem G. Meio e normas do homem no trabalho. Proposições. 2001 (Trabalho original publicado em 1947);12(2-3):35-6.

16. Triginelli DH. Relações e condições de trabalho na extração de granito no município de Vila Pavão - ES: compreender o trabalho para pensar a formação [dissertação]. Belo Horizonte: Universidade Federal de Minas Gerais; 2011.

17. Antunes R. Adeus ao trabalho? Ensaio sobre as metamorfoses e a centralidade do mundo do trabalho. 8. ed. São Paulo: Cortez; Campinas: Editora Unicamp; 2002. 288 p.

18. Rodrigues RC. Iniciação ao processo de trabalho. Belo Horizonte: Escola Judicial do Tribunal Regional do Trabalho da $3^{\mathrm{a}}$ Região. s.d. 36 f.

19. Gomes Júnior AB, Brandão GR, Lopes FT. Clínica do trabalho: vida e trabalho com qualidade no TRTMG. Relatório parcial. Belo Horizonte; 2015. 32 p.

20. Brasil. Consolidação das leis trabalhistas. 24. ed. São Paulo: Saraiva; 1998.

21. Bourdieu P. O poder simbólico. 6. ed. Rio de Janeiro: Bertrand Brasil; 2003. 248 p.

22. Madeira LM. O direito nas teorias sociológicas de Pierre Bourdieu e Niklas Luhmann. Direito Justiça. 2007 jun;33(1):19-39.

23. Santos MA. Uma leitura do campo jurídico em Bourdieu. Águia. 2011;1.

24. Levy P. O inexistente impacto da tecnologia [Internet]. Folha de S.Paulo. 1997 ago 17; Caderno Mais Autores [acesso em 2015 mar 20]. Disponível em: http://www1.folha.uol.com.br/fsp/mais/ fs170803.htm

25. Echternacht E. Atividade humana e gestão da saúde no trabalho: elementos para a reflexão a partir da abordagem ergológica. Laboreal. 2008;IV(1):46-55.

26. Schwartz Y. Le Paradigme ergologique ou un métier de philosophe. Toulouse: Octarès; 2000. 763 p.

27. Tribunal Regional do Trabalho da $4^{\mathrm{a}}$ Região. Aumento de demanda à Justiça do Trabalho gaúcha chega a quase $40 \%$ em cinco anos. TRT4 Notícias. 2015 mar [acesso em 2018 maio 16]. Disponível em: http://amatra4.org.br/publicacoes/cadernos/77noticias/914-aumento-de-demanda-a-justica-dotrabalho-gaucha-chega-a-quase-40-em-cinco-anos

28. Schwartz Y. Conceituando o trabalho, o visível e o invisível. Trab Educ Saúde. 2011;9 Suppl 1:19-45.

29. Assis RW. Os impactos das novas tecnologias nas formas de sociabilidade e savoir-faire dos operadores: um estado de caso no setor siderúrgico [dissertação]. Belo Horizonte: Universidade Federal de Minas Gerais; 2000.

30. Schwartz Y. Disciplina epistêmica disciplina ergológica: paideia e politeia. Pro-Posições. 2001 jan/abr;13(1 Suppl 37):126-49.

31. Schwartz Y. Os ingredientes da competência: um exercício necessário para uma questão insolúvel. Educ Soc. 1998 dez;19(65):1-20.

32. Schwartz Y. Trabalho e gestão: níveis, critérios, instâncias. In: Figueiredo M, Jussara B, Athayde M, Denise A, organizadores. Labirintos do trabalho: interrogações e olhares sobre o trabalho vivo. Rio de Janeiro: DP\&A; 2004. p. 23-33.

33. Teixeira LP. Pedido de autorização para republicação de material [mensagem pessoal]. 2018 maio 11. Mensagem recebida por lucinept@trt3. jus.br. 